\title{
CHARACTERISATION OF EPOXIDISED TRIMETHYLOLPROPANE TRIOLEATE: NMR AND THERMOGRAVIMETRIC ANALYSIS
}

MEI YEE CHEONG*; ZAFARIZAL ALDRIN AZIZUL HASAN ${ }^{*}$ and ZAINAB IDRIS*

\begin{abstract}
Epoxy or oxirane compounds have attracted considerable interest and commercial importance in recent years. The study on the synthesis of trimethylolpropane (TMP) ester is well established. However, the study on the epoxidation of the oleyl-based TMP is still limited. Therefore, the present research concerns the characterisation of epoxidised TMP trioleate which could be used as plasticiser, high stability biolubricants and feedstock for the subsequent reaction such as acrylation to produce bio-based polymer and resin. The effect of the molar ratio of ethylenic unsaturation in TMP trioleate to formic acid for in situ peroxidation has been investigated. The resultant epoxidised TMP trioleate containing different numbers of epoxide groups/molecule were synthesised. The high ratio of formic acid to ethylenic unsaturation in TMP trioleate is unfavourable for in situ epoxidation as it yielded lower amount of epoxy ester. The epoxidised TMP tritrioleate was synthesised, confirmed by Fourier transform infrared (FTIR) and the degree of epoxidation (DOE) was quantified by nuclear magnetic resonance (NMR). The epoxidised TMP trioleate which contained TMP 9, 10-epoxystearic acid and TMP 9, 10, 12, 13-diepoxystearic acid were also identified. The thermal stability were compared and it was found that the epoxidised TMP trioleate has lower thermal degradation temperature than TMP trioleate.
\end{abstract}

Keywords: epoxidation, trimethylolpropane trioleate, epoxidised trimethylolpropane trioleate.

Date received: 7 November 2017; Sent for revision: 30 November 2017; Received in final form: 14 August 2018; Accepted: 20 December 2018.

\section{INTRODUCTION}

Trimethylolpropane (TMP) trioleate from vegetable triglycerides has been used intensively as the base stock in lubricant formulation to replace mineral-based lubricant mainly due to ecological concern, renewability and sustainability (Yunus et al., 2002). TMP trioleate has been epoxidised to improve the oxidative stability due to its unsaturated bonds in the fatty acid chains which is a vulnerable site for oxidation as it is influenced

* Malaysian Palm Oil Board,

6 Persiaran Institusi, Bandar Baru Bangi,

43000 Kajang, Selangor, Malaysia.

E-mail: cheongmy@mpob.gov.my by light, heat, air and water activity. The initial rapid oxidation of polyunsaturated fatty acids provided a transient pool of peroxides that led to the formation of aldehydes, ketones, and acids as secondary compounds in rancidified products. Polymerisation with ester linkages are likely contributors to the higher molecular weight materials formed and the resulting increase in viscosity during oxidation. Oxidation is also causing the decrease in functionality, breakdown of volatile and corrosive products, and diminishing of the desirable properties (Naidir et al., 2012). However, epoxidation process, which is slightly different from oxidation can be utilised to form epoxidised TMP trioleate which is a fairly stable derivative than TMP trioleate. Epoxidised TMP trioleate can be used 
interchangeably with epoxidised oils to be used as a plasticiser and stabiliser in plastic materials especially polyvinylchloride (Benecke et al., 2004), biodegradable but stable at high temperature lubricants (Wu et al., 2000; Adhvaryu et al., 2002), pigment dispersing agent (Farkas, 1999), feedstock for ring-opening process with acrylic acid to produce epoxy acrylate in ultra violet (UV) cure copolymer (Cheong et al., 2009; Saithat et al., 2013; Salih et al., 2015) and polyol production (Hassan et al., 2011). The epoxy TMP ester could be polymerised to form plastic materials such as epoxy ester-co-styrene/ divinylbenzene resins (Li et al., 2001; Li and Larock, 2000; 2001; 2002), sheet molding compound resin (Lu et al., 2005), epoxy ester thermosetting allyl resins (Luo et al., 2011), organo clay nanocomposite (Tanrattanakul and Saithai, 2009), hydrogel (Xu et al., 2008), matrix in fibres-reinforced composites (Khot et al., 2001; Liu et al., 2002; 2006; Boquillon, 2006), epoxy-anhydride polyester resin (Xiao et al., 2011) and poly(lactic acid)/epoxidised oil composite (Chieng et al., 2017). In most cases, the in situ epoxidation technique was employed to the feedstock esters with fatty acids derived from soyabean oil, palm oil and any other vegetable oils.

A suitable oxidising agent aids in the elimination of double bonds during epoxidation to convert them into oxirane ring. The in situ epoxidation process namely, the Prileschajew oxidation route (Scotti et al., 2015; Prileschajew, 1909) is generally carried out by peracetic or peroxyformic acids, which are executed in situ due to the safety concerns, since the concentrated peracid is unstable and explosive if generated externally (Goud et al., 2007). The in situ epoxidation reaction takes place in two steps; step one ensures the formation of peroxyformic acid, while the reaction of peroxyformic acid with the ethylenic unsaturation to form the oxirane ring takes place in the second step (Naidir et al., 2012).

The most common method to determine epoxide concentrations in oxidised oil is the hydrogen bromide $(\mathrm{HBr})$ method involving direct titration of oil with $\mathrm{HBr}$-acetic acid solution (AOCS Method Cd 9-57) (AOCS, 2009). However, this method is not suitable to oxidised oils, because $\alpha$ - and $\beta$-unsaturated carbonyls and conjugated dienes formed during oil oxidation can also react with $\mathrm{HBr}$, resulting in overestimation of epoxide content. However, in this project, the formation of these side reactants during epoxidation is negligible due to absence of rancid fatty acids in the sample. The ${ }^{1} \mathrm{H}$-nuclear magnetic resonance (NMR) was proposed to be applied to measure the amount of epoxides and the secondary oxidation products such as aldehydes, ketones, and acids by identifying their corresponding chemical shifts and their integrations in rancid TMP trioleate sample.
Study on the characteristic of TMP 9, 10-epoxystearic acid has not been reported although the kinetics of the epoxidation of TMP ester has been published (Naidir et al., 2012). Although the characterisation of epoxidised TMP ester in lubricant application has been done, the quantification of epoxy ring is crucial for quality and reaction monitoring purposes. The thermal stability of the epoxidised TMP trioleate also has not been studied. In this research, commercially available TMP ester in the form of TMP tritrioleate was epoxidised and confirmed by Fourier transform infrared (FTIR) while NMR was used to quantify the degree of epoxidation. The thermal stability of the both samples were analysed by thermogravimetric analysis (TGA).

\section{MATERIALS AND METHODS}

\section{Materials}

TMP trioleate (Radialube 7557) was kindly donated by Oleon Sdn Bhd (Malaysia). The sample consisted of $72.7 \%$ of TMP trioleate and served as a starting material for the epoxidation reaction. The composition of TMP ester was analysed using gas chromatography (GC) following the method as described (Yunus et al., 2002) and the composition of the TMP trioleate is shown in Table 1 while the GC chromatogram is as shown in Figure 1. Industrial grade hydrogen peroxide $50 \% \mathrm{v} / \mathrm{v}$ and formic acid $94 \% \mathrm{v} / \mathrm{v}$ was supplied by BASF (China). Sodium thiosulphate and Wijs solution were from Merck KGaA (Germany). Glacial acetic acid was obtained from Friendemann Schmidt (Australia). The $\mathrm{HBr}$ and deuterated chloroform were purchased from Sigma-Aldrich (USA). All chemicals were used as received.

TABLE 1. COMPOSITION OF TRIMETHYLOLPROPANE (TMP) TRIOLEATE

\begin{tabular}{lc}
\hline TMP ester & Content $(\%)$ \\
\hline TMP monooleate & 0.044 \\
TMP dioleate & 4.22 \\
TMP trioleate & 72.70 \\
\hline
\end{tabular}

Synthesis of epoxidised TMP trioleate. The epoxidation of TMP ester was done to introduce oxirane functionality to the double bonds in trioleate chain. Iodine value of TMP trioleate was used to determine the mole of ethylenic unsaturation contained in the ester and the molar ratios of TMP trioleate/formic acid/hydrogen peroxide used was 1:1:2.5, 1:2.5:2.5 and 1:4:2.5 $(\mathrm{w} / \mathrm{w})$. About $100 \mathrm{~g}$ of TMP trioleate $(0.34 \mathrm{~mol}$ of ethylenic unsaturation) was weighed into a three- 


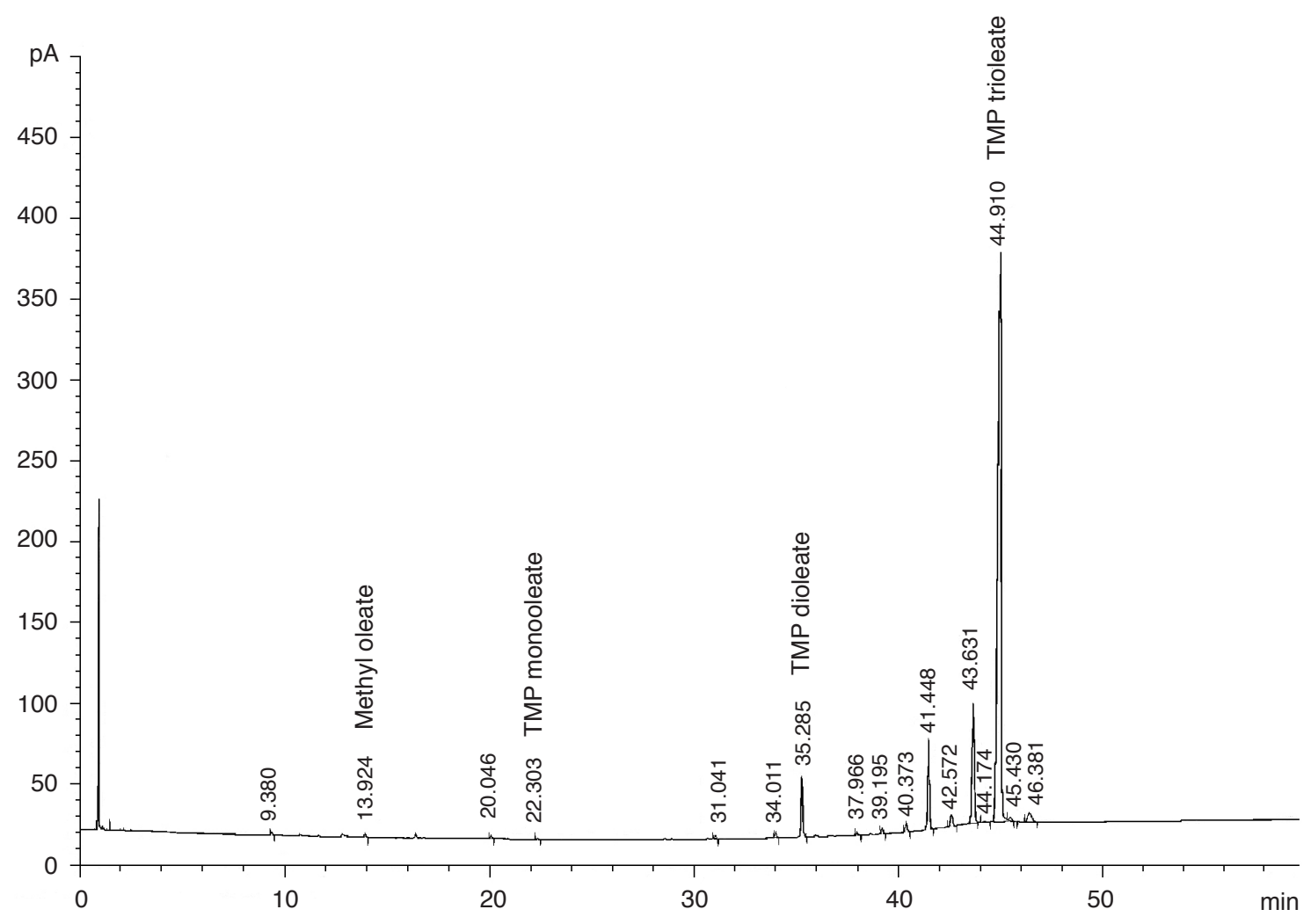

Figure 1. GC chromatogram showing methyl oleate, TMP monooleate, TMP dioleate and TMP trioleate peaks after 13.9, 22.3, 35.3 and 44.9 min, respectively.

necked flask equipped with a reflux condenser, thermometer and magnetic stirrer. For 1:2.5 mole ratio of formic acid to hydrogen peroxide, a solution of peroxyformic acid made in situ has $15.65 \mathrm{~g}$ formic acid $(0.34 \mathrm{~mol})$ and $57.82 \mathrm{~g}$ hydrogen peroxide $(0.85$ mol). The pre-mixed solution was added slowly in dropwise manner into pre-heated TMP trioleate at $40^{\circ} \mathrm{C}$ while stirring so that the temperature can maintain below $60^{\circ} \mathrm{C}$ since the reaction is highly exothermic. The epoxidation process was monitored after particular time intervals by oxirane oxygen content (\%) until the value is constant after $6 \mathrm{hr}$. The reaction mixture was poured into a separatory funnel and the aqueous layer drawn off. The crude product was washed with distilled water repeatedly until a pH 7 was obtained. The oil phase was dried with anhydrous sodium sulphate and then filtered. Finally, the residual water was removed using an evaporator at $45^{\circ} \mathrm{C}$ under low pressure.

\section{Characterisation of TMP Trioleate and Epoxidised TMP Trioleate}

The ${ }^{1} \mathrm{H}-\mathrm{NMR},{ }^{13} \mathrm{C}-\mathrm{NMR}$ spectra was recorded qualitatively by a JEOL $\AA$ Resonance NMR spectrometer (Japan) at a frequency of $600 \mathrm{MHz}$ using chloroform-d as solvent. The FTIR spectra of the samples were recorded by a Perkin Elmer ${ }^{\circledR}$ Spectrum 100 with Universal Attenuated Total Reflectance (ATR) (USA) from 400 to $4000 \mathrm{~cm}^{-1}$.
Viscosity was measured on a Brookfield Rheometer, DV-III Ultra with RV3 spindle attached.

The iodine value of TMP trioleate was needed to calculate the theoretical maximum oxirane oxygen. It was determined according to the PORIM Test Method (Wijs solution) and expressed as $\mathrm{g} \mathrm{I}_{2} / 100 \mathrm{~g}$.

$$
\text { Iodine value }=\frac{(\mathrm{B}-\mathrm{S}) \times \mathrm{N} \times 12.69}{\mathrm{~W}}
$$

where, $B$ is volume of sodium thiosulphate required for titration of the blank, $\mathrm{ml}, S$ is the required sodium thiosulphate required for titration of the sample, $\mathrm{ml}, \mathrm{N}$ is the normality of sodium thiosulfate solution and $W$ is the weight of the sample, g.

The concentration of epoxides in TMP 9, 10-epoxystearic acid was determined by AOCS Method Cd 9-57 using $\mathrm{HBr}$ (AOCS, 2009). As HBr is sensitive to air and light, the $\mathrm{HBr}$-acetic acid solution was standardised each time before use. Crystal violet solution $\left(0.001 \mathrm{~g} \mathrm{ml}^{-1}\right.$ in glacial acetic acid) was used as the indicator, and the sample was titrated to a blue-green end point. The determination was performed in triplicate for each sample. The concentration of epoxides was reported as oxirane oxygen content, $\%$.

$$
\text { Oxirane oxygen content }(\%)=\frac{\mathrm{V} \times \mathrm{N} \times 1.6}{\mathrm{M}}
$$


where, $V$ is the volume of $\mathrm{HBr}$ to titrate the sample in $\mathrm{ml}, \mathrm{N}$ is the normality of the $\mathrm{HBr}$ solution in mol litre ${ }^{-1}$, and $M$ is the mass of sample in $\mathrm{g}$.

The TGA was performed on a Simultaneous Thermal Analyser, STA 6000, Perkin Elmer with a heating rate of $10^{\circ} \mathrm{C} \mathrm{min}{ }^{-1}$ in a nitrogen atmosphere from $50^{\circ} \mathrm{C}$ to $900^{\circ} \mathrm{C}$. The temperatures at initial, $50 \%$, end set and maximum peak for weight loss were determined.

\section{Data Analysis}

The conversion of unsaturated fatty acids to oxirane was determined using two analyses: percentage of oxirane oxygen and iodine value. Firstly, the theoretical maximum oxirane oxygen was obtained by using the following Equation (3):

$$
\begin{gathered}
\text { Theoretical } \\
\text { maximum } \\
\text { oxirane oxygen }
\end{gathered}=\frac{\left(\mathrm{IV}_{\mathrm{o}} / 2 \mathrm{~A}_{\mathrm{i}}\right)}{100+\left(\mathrm{IV}_{\mathrm{o}} / 2 \mathrm{~A}_{\mathrm{i}}\right) \mathrm{A}_{\mathrm{o}}} \times \mathrm{A}_{\mathrm{o}} \times 100
$$

The values of $A_{i}=126.9$ and $A_{o}=16.0$ represent the atomic numbers for iodine and oxygen, respectively. The initial iodine value $\left(\mathrm{IV}_{\mathrm{o}}\right)$ of the TMP trioleate was determined to be $84.64 \mathrm{~g} \mathrm{I}_{2} / 100$ $\mathrm{g}$ from iodine value analysis, hence the theoretical maximum oxirane oxygen is $5.07 \%$.

The number of epoxide groups per molecule of epoxidised TMP trioleate was calculated from the ${ }^{1} \mathrm{H}-\mathrm{NMR}$ spectrum by using the integrated peak at $\delta=5.27-5.38 \mathrm{ppm}$ for the fatty acids unsaturation and the integrated peak at $\delta=2.83-3.11$ for epoxy group (Saithai et al., 2013). The proton at $\delta=4.00$ was used as internal standard. The peak intensity ratio between these corresponding peaks representing epoxides groups to unsaturation is the yield of epoxidation. The degree of epoxidation (DOE), however is as determined from Equation (4) which was calculated by dividing experimental oxirane oxygen content by the theoretical oxirane oxygen:

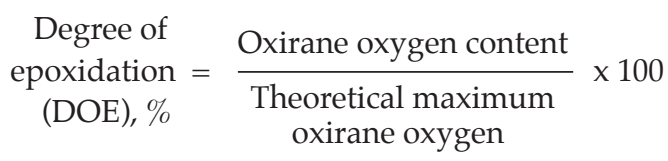

\section{RESULTS AND DISCUSSION}

The epoxidation of TMP trioleate was performed at medium temperature, $40^{\circ} \mathrm{C}$ and controlled below $60^{\circ} \mathrm{C}$. Temperature increment is significantly detrimental for achieving high oxirane numbers, as the selectivity to ring-opening reactions increases (Champanella et al., 2008). Although activation energy is needed for the epoxidation but it is a highly exothermic process with high temperature also accelerates decomposition of the hydrogen peroxide and promotes unwanted ring-opening reaction. In the in situ reaction, the peroxyformic acid formation and reaction with the double bond occur simultaneously leading to the eventual consumption of a stoichiometric amount of hydrogen peroxide as shown in Figure 2. The reaction conversion was determined based on the epoxidation of the double bond, present in the fatty acids chain of TMP trioleate, into oxirane oxygen. The properties of the TMP trioleate and the effect of various molar ratio of formic acid to unsaturated ester on epoxy TMP trioleate yield, conversion and DOE are shown in Table 2. A high degree of DOE was achieved by utilising 1:1:2.5 mole ratio of TMP trioleate/formic acid/hydrogen peroxide. This was evident in the lack of protons from the unsaturated fatty acids in its ${ }^{1} \mathrm{H}-\mathrm{NMR}$ spectrum of the epoxidised TMP trioleate. High molar ratios of formic acid to ethylenic unsaturation presented in the TMP ester caused excessive ring opening with resulting low yields of the desired epoxy ester. A high acid value indicated a high free fatty acid content. It was believed that these free fatty acids were the result of hydrolysis from TMP trioleate. The epoxidised TMP trioleate which contained TMP 9, 10-epoxystearic acid and TMP 9, 10, 12, 13-diepoxystearic acid were identified and confirmed by FTIR, ${ }^{1} \mathrm{H}-\mathrm{NMR}$ and ${ }^{13} \mathrm{C}-\mathrm{NMR}$.

The effect of TMP trioleate/formic acid/ hydrogen peroxide ratio on the percentage of oxirane oxygen content is shown in Figure 3. The reaction conversion was determined based on the epoxidation of the double bond, present in the oleic acid chain of TMP trioleate, into oxirane oxygen. At 1:1:2.5 mole ratio of TMP trioleate, formic acid and hydrogen peroxide, the rate of reaction was considerably fast and the reaction took less time to reach its completion in $4 \mathrm{hr}$ even though the initial temperature of the reaction was maintained considerably low between $40^{\circ} \mathrm{C}-60^{\circ} \mathrm{C}$ to prevent cleavage of oxirane bond. The oxirane oxygen content was used to analyse the final yield of epoxy ester in which $89.5 \%$ was attained in the reaction while the DOE attained was $85.5 \%$. At 1:2.5 mole ratio of ethylenic unsaturation in TMP trioleate to formic acid, the DOE achieved was $53.1 \%$. The low number of epoxide per molecule also contributed to lower yield of epoxy ester at $52.4 \%$. This was attributed to the longer duration time needed to complete the reaction which might contribute towards the degradation of oxirane ring due to high oxidising potential of peroxyformic acid. The high molar ratio of aliphatic acid to hydrogen peroxide, high temperature, high acidity, and long reaction time are known to be deleterious to the survival of an epoxy compound (Gall and Greenspan, 1955).

When using 1:4 mole ratio of ethylenic unsaturation to formic acid, the yield of epoxy ester went down to $32.5 \%$ while the DOE achieved was 


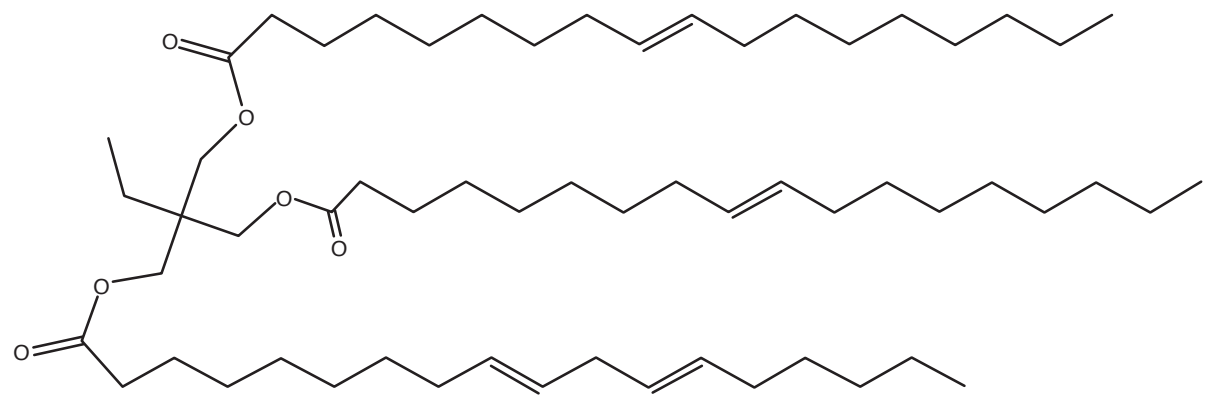<smiles>CC(=O)OC(C)C(C)C(=O)O</smiles><smiles>CCCCCCCCCC(=O)OCC(CC)(COC(=O)CCCCCCCC1OC1CCCCCCCC)COC(=O)CCCCCCCC1OC1CCCCCCCC</smiles>

Figure 2. Epoxidation of TMP trioleate.

TABLE 2. THE PROPERTIES OF TRIMETHYLOLPROPANE (TMP) TRIOLEATE AND THE EFFECT OF VARIOUS MOLAR RATIO OF FORMIC ACID TO UNSATURATED ESTER ON EPOXY TMP TRIOLEATE YIELD, CONVERSION AND DEGREE OF EPOXIDATION (DOE)

\begin{tabular}{lcccc}
\hline Properties & TMP trioleate & \multicolumn{3}{c}{ Epoxidised TMP trioleate } \\
\hline Molar ratios of unsaturated & - & $1: 1: 2.5$ & $1: 2.5: 2.5$ & $1: 4: 2.5$ \\
$\quad$ ester/formic acid/hydrogen peroxide & & & & \\
Appearance & Pale yellow liquid & Clear liquid & Clear liquid & Clear liquid \\
Density $\left(\mathrm{g} \mathrm{cm}^{-3}\right.$ ) & 0.937 & 0.962 & 0.966 & 0.965 \\
Viscosity at $25^{\circ} \mathrm{C}(\mathrm{mPa} . \mathrm{s})$ & $103.3 \pm 2.9$ & $535.0 \pm 0.1$ & $450.0 \pm 0.2$ & $380.0 \pm 0.2$ \\
Moisture $(\%)$ & 0.01 & 0.25 & 0.25 & 0.28 \\
Acid value $\left(\mathrm{mg} \mathrm{KOH} \mathrm{g}^{-1}\right)$ & $0.23 \pm 0.03$ & $1.48 \pm 0.1$ & $5.70 \pm 0.9$ & $10.35 \pm 0.8$ \\
Oxirane oxygen content $(\%)$ & 0.01 & $4.33 \pm 0.03$ & $2.72 \pm 0.07$ & $1.66 \pm 0.04$ \\
Degree of epoxidation $(\%)$ & - & 85.5 & 53.1 & 32.4 \\
Yield epoxy ester $(\%)$ & - & 89.5 & 52.4 & 32.5 \\
\hline
\end{tabular}

Note: The data represent $\pm \mathrm{sd}$ of three replicates.

$32.4 \%$. High molar ratio of formic acid to hydrogen peroxide too will cause excessive ring opening which resulted in low yield of the desired epoxy ester and formation of hydroperoxides and aldehydes (Xia et al., 2015). The reaction also generated free fatty acids due to the hydrolysis reaction as indicated by a high acid value. Therefore, the 1:1 mole ratio of formic acid to ethylenic unsaturation in TMP trioleate is suitable for the in situ epoxidation reaction to be highly effective.
The FTIR spectra of TMP trioleate and its epoxidised form are as shown in Figures $4 a$ and $4 b$. The peaks found in the TMP trioleate are $723 \mathrm{~cm}^{-1}$ (methyl symmetric deformation, cis isomer), $997 \mathrm{~cm}^{-1}$ (=C-H bend), 1158, 1238 (C-O, ester, antisymmetric stretch), $1380 \mathrm{~cm}^{-1}$ (methyl symmetric deformation), $1464 \mathrm{~cm}^{-1}$ (methyl antisymmetric deformation), $1742 \mathrm{~cm}^{-1}$ (ester, aliphatic $\mathrm{C}=\mathrm{O}$ stretch), $3007 \mathrm{~cm}^{-1}$ (=C-H stretch due to $c$ is unsaturated fatty acid). The main comparison between the both FTIR spectra of 


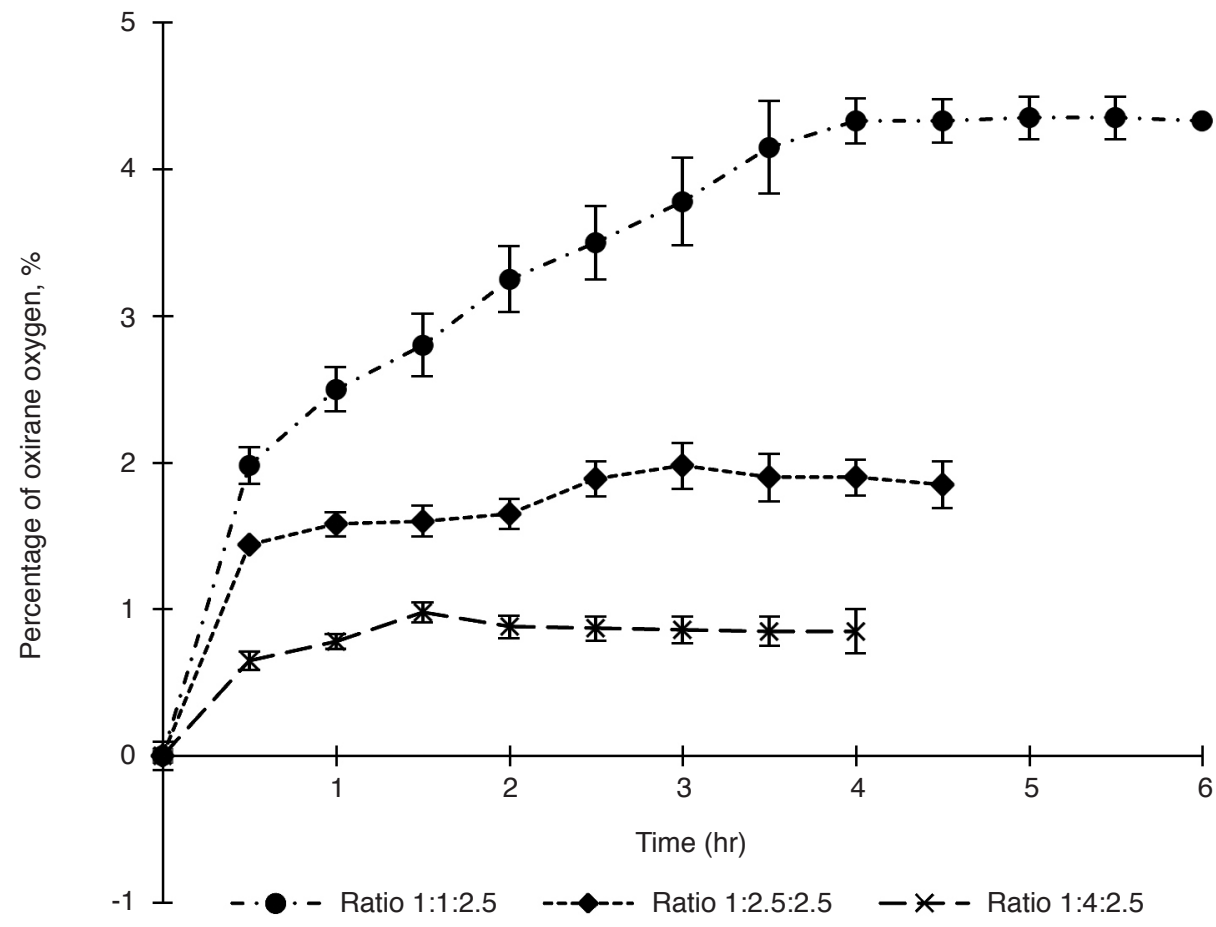

Figure 3. Effect of the ratio of TMP trioleate to formic acid and hydrogen peroxide on the percentage of oxirane oxygen content. The data represent \pm standard deviation of three replicates.

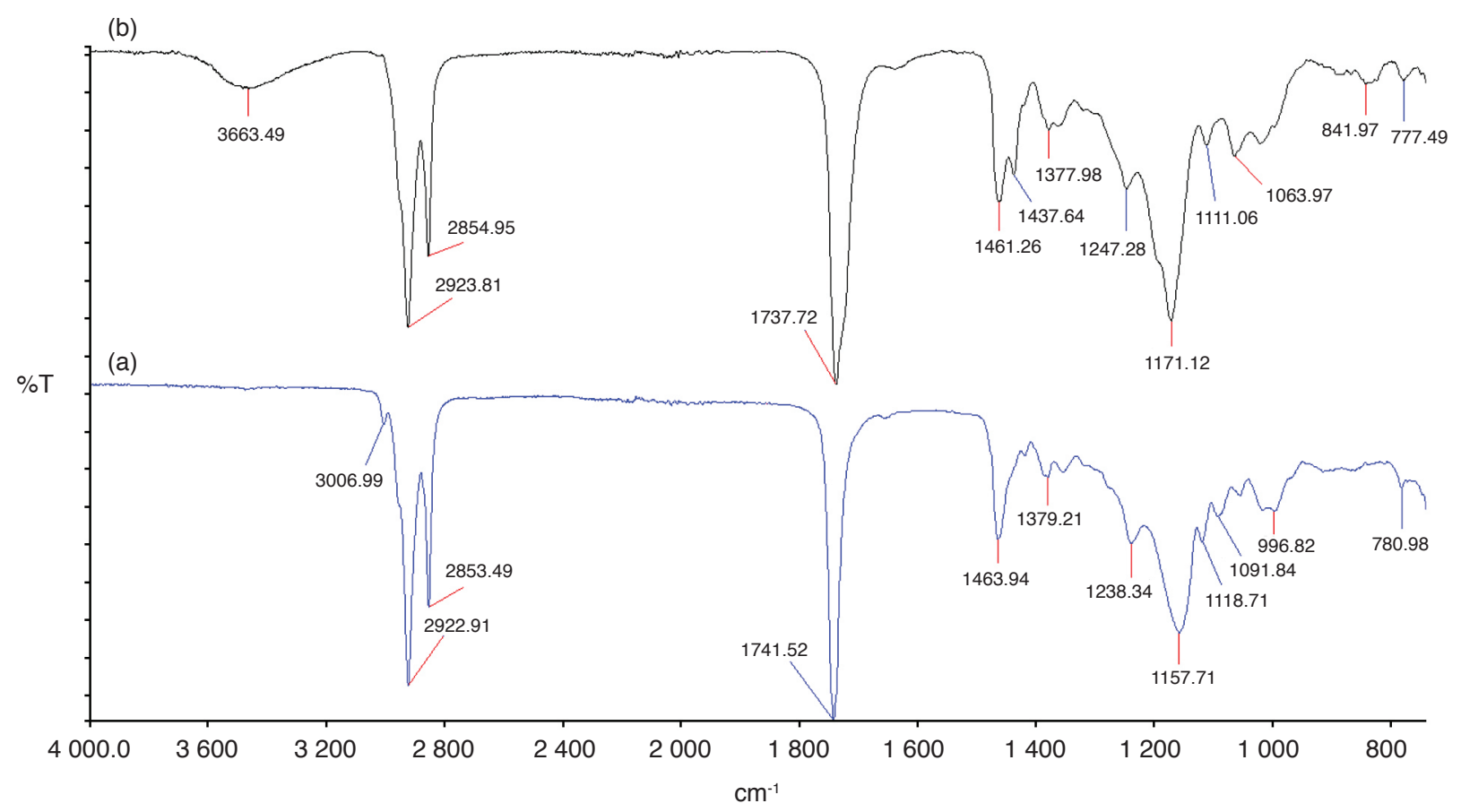

Figure 4. FTIR spectra of (a) TMP trioleate and (b) epoxidised TMP trioleate. The epoxy group of epoxidised TMP trioleate was denoted at $842 \mathrm{~cm}^{-1}$.

TMP trioleate and its epoxidised form is obviously the new absorption bands in the spectrum at 842 $\mathrm{cm}^{-1}$, which is attributed to the C-O-C asymmetric bending. The other absorption bands obtained for epoxidised TMP ester were epoxy group at $778 \mathrm{~cm}^{-1}$ and $842 \mathrm{~cm}^{-1}$, the characteristic of hydrogen-bonded $\mathrm{OH}$ groups which implied minute amount of moisture at $3463 \mathrm{~cm}^{-1}$ and disappearance of double bonds at $3007 \mathrm{~cm}^{-1}$.

The ${ }^{1} \mathrm{H}-\mathrm{NMR}$ spectroscopy was used to verify the TMP trioleate and its epoxidised form which comprised of TMP 9, 10-epoxystearic acid and TMP 9, 10, 12, 13-diepoxystearic acid. The deuterated chloroform were used to dissolve the sample and its 
${ }^{1} \mathrm{H}-\mathrm{NMR}$ spectra were recorded at $\delta 7.24 \mathrm{ppm}$. Figure 5 shows the ${ }^{1} \mathrm{H}-\mathrm{NMR}$ spectrum of TMP trioleate, its integration and the chemical shift assignment with its corresponding structure. The characteristic peak of the TMP backbone can be observed clearly. The peak signal at $\delta 0.84-0.88$ ppm with an integration corresponded to the 12 protons of the terminal methyl protons of $\mathrm{H}_{\mathrm{a}}\left(-\mathrm{CH}_{2} \mathrm{CH}_{3}\right)$. The two protons at bridging methylene group adjacent to the terminal methyl group at $\delta 1.43-1.48$ ppm assigned to $\mathrm{H}_{c}$ $\left(-\mathrm{CH}_{2}-\mathrm{CH}_{3}\right)$ which had quadruple splitting. Most of the bridging methylene overlapped with $\delta 1.23-1.33$ ppm at $\mathrm{H}_{\mathrm{b}}\left(-\mathrm{CH}_{2} \mathrm{CH}_{2} \mathrm{CH}_{2}^{-}\right)$and $\left[-\left(\mathrm{CH}_{2}\right)_{3} \mathrm{CCH}_{2} \mathrm{CH}_{3}\right]$ due to shielding effect being surrounded by high electron density. The six protons each were found in bridging methylene group at $\beta$ position at $\delta$ $1.56-1.60$ ppm of $\mathrm{H}_{\mathrm{d}}\left(-\mathrm{CH}_{2}-\mathrm{CH}_{2} \mathrm{C}=\mathrm{O}-\right)$ and at $\alpha$ position $\delta 2.25$ - 2.32 ppm of $\mathrm{H}_{\mathrm{f}}\left(-\mathrm{CH}_{2} \mathrm{CH}_{2}-\mathrm{C}=\mathrm{O}-\right)$ respectively. The TMP backbone which was used as internal standard had six protons, the proton adjacent to ester link was assigned to the $\delta 3.97$. $4.02 \mathrm{ppm}$ of $\mathrm{H}_{\mathrm{h}}\left(-\alpha-\mathrm{CH}_{2}-\mathrm{O}-\mathrm{C}\right)$ in the structure. The bridging methylene group adjacent to the vinyl group at $\delta 1.95-2.05$ ppm or $\mathrm{H}_{\mathrm{e}}\left(-\mathrm{CH}_{2} \mathrm{CH}_{2}-\mathrm{CH}=\mathrm{CH}\right)$ with integration value of 11 protons suggested the sample could be a mixture of TMP attached with fully unsaturated and saturated fatty acid chains.

The presence of vinyl group of unsaturated double bonds was confirmed with $\delta 5.27-5.38$ ppm of methine protons $\mathrm{H}_{\mathrm{i}}(-\mathrm{CH}=\mathrm{CH}-)$ in the structure with integration corresponding to 5.72 . The bridging methylene group in between the two methine groups is assigned at $\delta 2.73-2.77$ ppm of $\mathrm{H}_{\mathrm{g}}\left(-\mathrm{CH}=\mathrm{CH}-\mathrm{CH}_{2}-\mathrm{CH}=\mathrm{CH}-\right)$ which showed linoleic

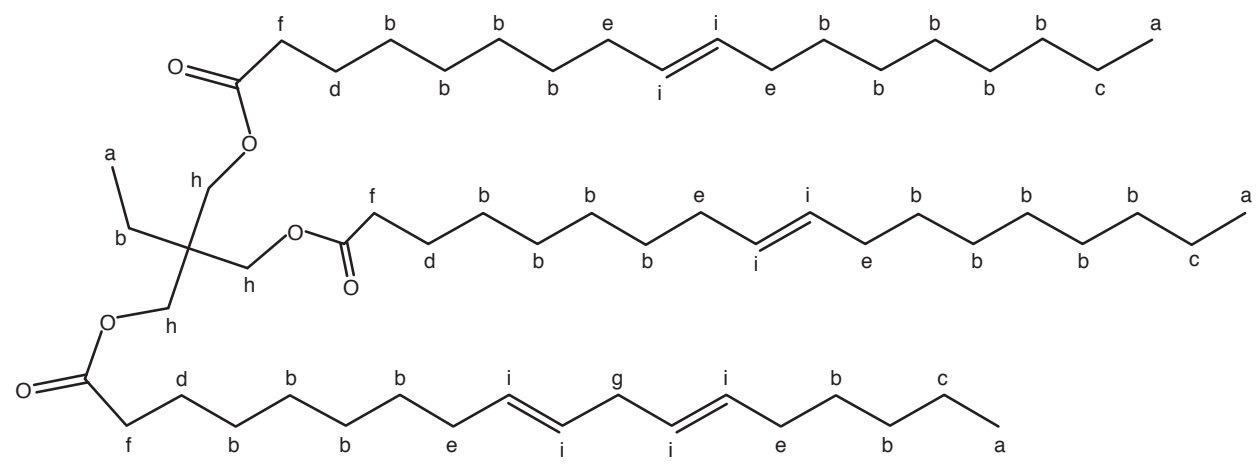

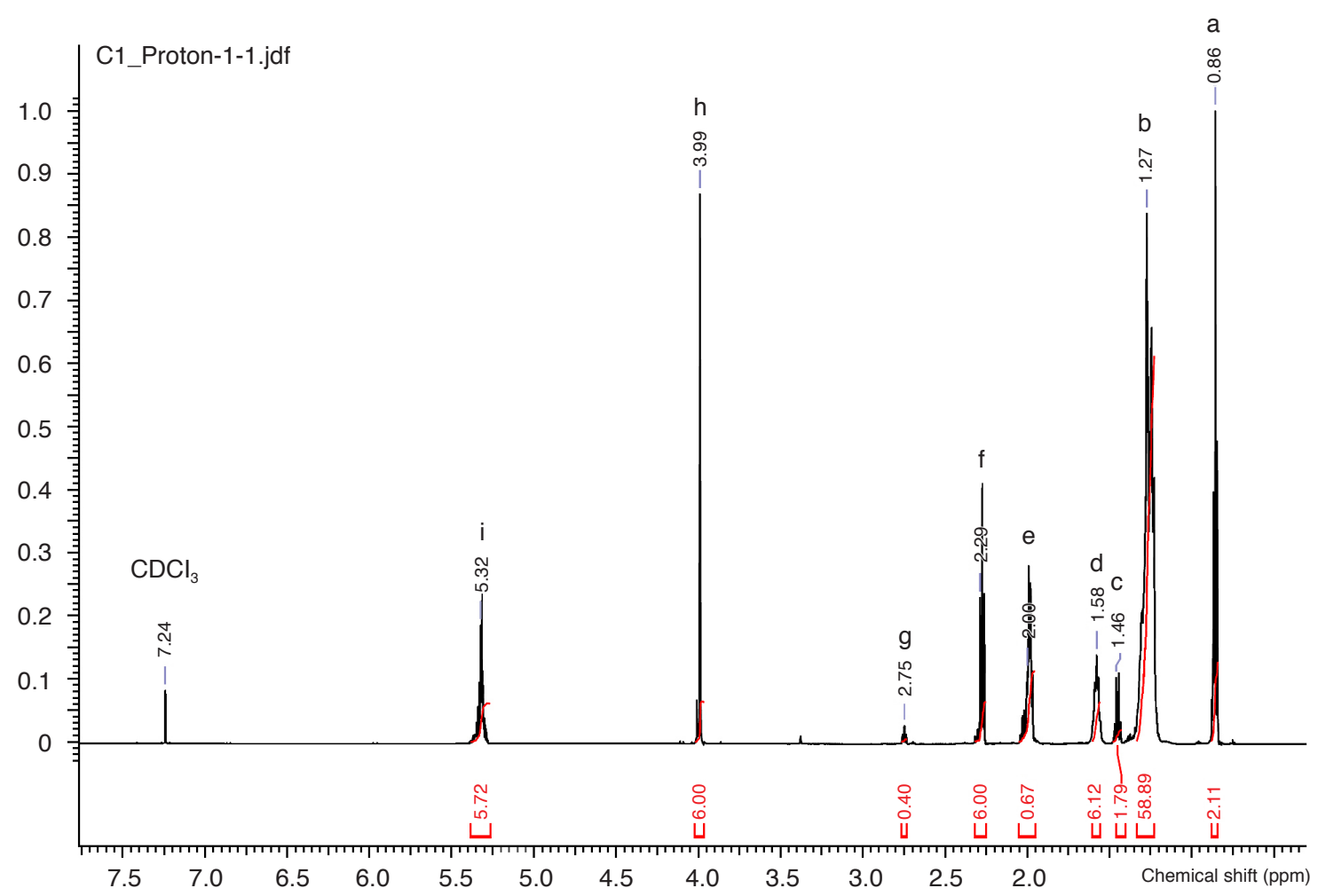

Figure 5. Integration of ${ }^{1} H-N M R$ spectrum of TMP trioleate with its structure. The integrations of the double bonds at $\delta 5.27-5.41$ ppm in $H_{a}$ was made by taking the signals of protons $\left(\alpha-\mathrm{CH}_{2}-\mathrm{O}-\mathrm{C}\right)$ in $\mathrm{H}_{h}$ at $\delta 3.97-4.02 \mathrm{ppm}$ as internal standards. The area of the internal standard was calibrated as 6.00 as the number of $\alpha$-protons is 6 . 
fatty acid moiety in the TMP trioleate sample. The epoxidation reaction was monitored for presence of TMP 9, 10-epoxystearic acid and TMP 9, 10, 12, 13-diepoxystearic acid. The double bonds remaining at $\delta 5.27$ - 5.38 ppm indicated partial epoxidation.

Figure 6 shows the integrated ${ }^{1} \mathrm{H}-\mathrm{NMR}$ spectrum of epoxidised TMP trioleate and their chemical shift assignment. The peak signal at $\delta 0.84-0.89 \mathrm{ppm}$ with an integration corresponding to 12 protons of the terminal methyl protons of $\mathrm{H}_{\mathrm{a}}\left(-\mathrm{CH}_{2} \mathrm{CH}_{3}\right)$. The bridging methylene shielded by high electron density at $\delta 1.21-1.35$ ppm corresponded to $\mathrm{H}_{\mathrm{b}}\left(-\mathrm{CH}_{2} \mathrm{CH}_{2} \mathrm{CH}_{2}-\right)$ and $\left[-\left(\mathrm{CH}_{2}\right)_{3} \mathrm{CCH}_{2} \mathrm{CH}_{3}\right]$. The protons at bridging methylene group adjacent to the methyl terminal at $\delta 1.36-1.42 \mathrm{ppm}$ assigned to $\mathrm{H}_{c}\left(-\mathrm{CH}_{2} \mathrm{CH}_{2} \mathrm{CH}_{3}\right)$ although not easily distinguished from the dense peaks. The bridging methylene group at $\beta$ position corresponded to $\delta 1.56-1.60 \mathrm{ppm}$ of $\mathrm{H}_{\mathrm{e}}$ $\left(-\mathrm{CH}_{2}-\mathrm{CH}_{2} \mathrm{C}=\mathrm{O}-\right)$ while at $\alpha$ position, corresponded to $\delta 2.26-2.32$ ppm of $\mathrm{H}_{\mathrm{g}}\left(-\mathrm{CH}_{2} \mathrm{CH}_{2}-\mathrm{C}=\mathrm{O}-\right)$. Both chemical shifts of these methylene groups had six proton respectively when integrated. The methylene group at the TMP backbone which was used as internal standard had six protons, whereby these protons adjacent to the ester link were assigned to $\delta 3.96-4.02$ ppm of $\mathrm{H}_{\mathrm{k}}\left(\alpha-\mathrm{CH}_{2}-\mathrm{O}-\mathrm{C}-\right)$. The peak signal with an integration corresponding to 12 protons also found at $\delta 1.45-1.48$ ppm of $H_{d}$

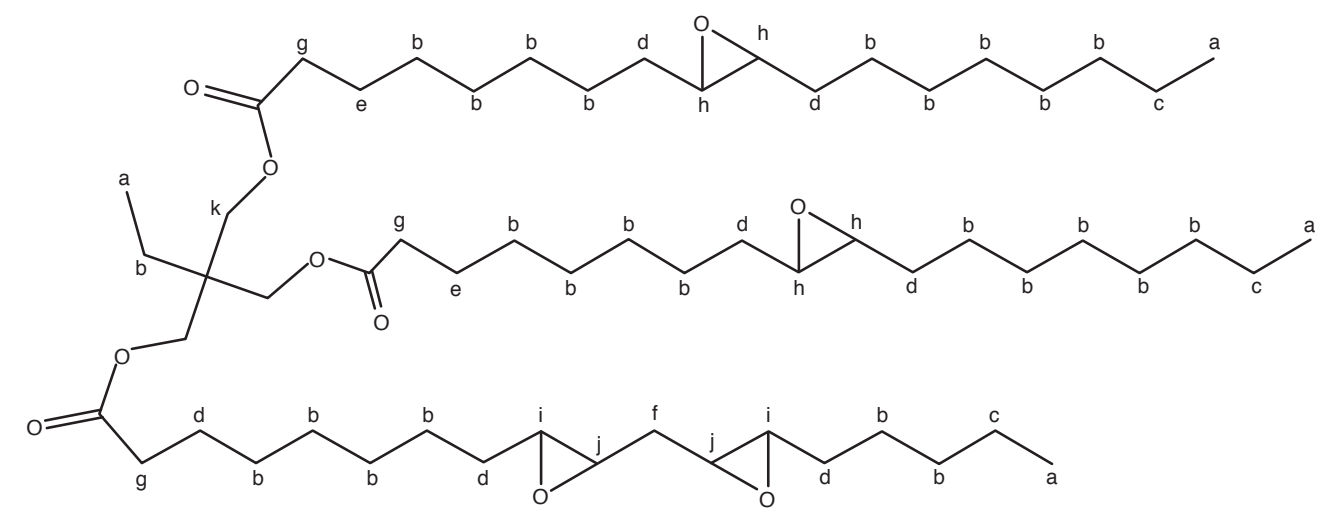

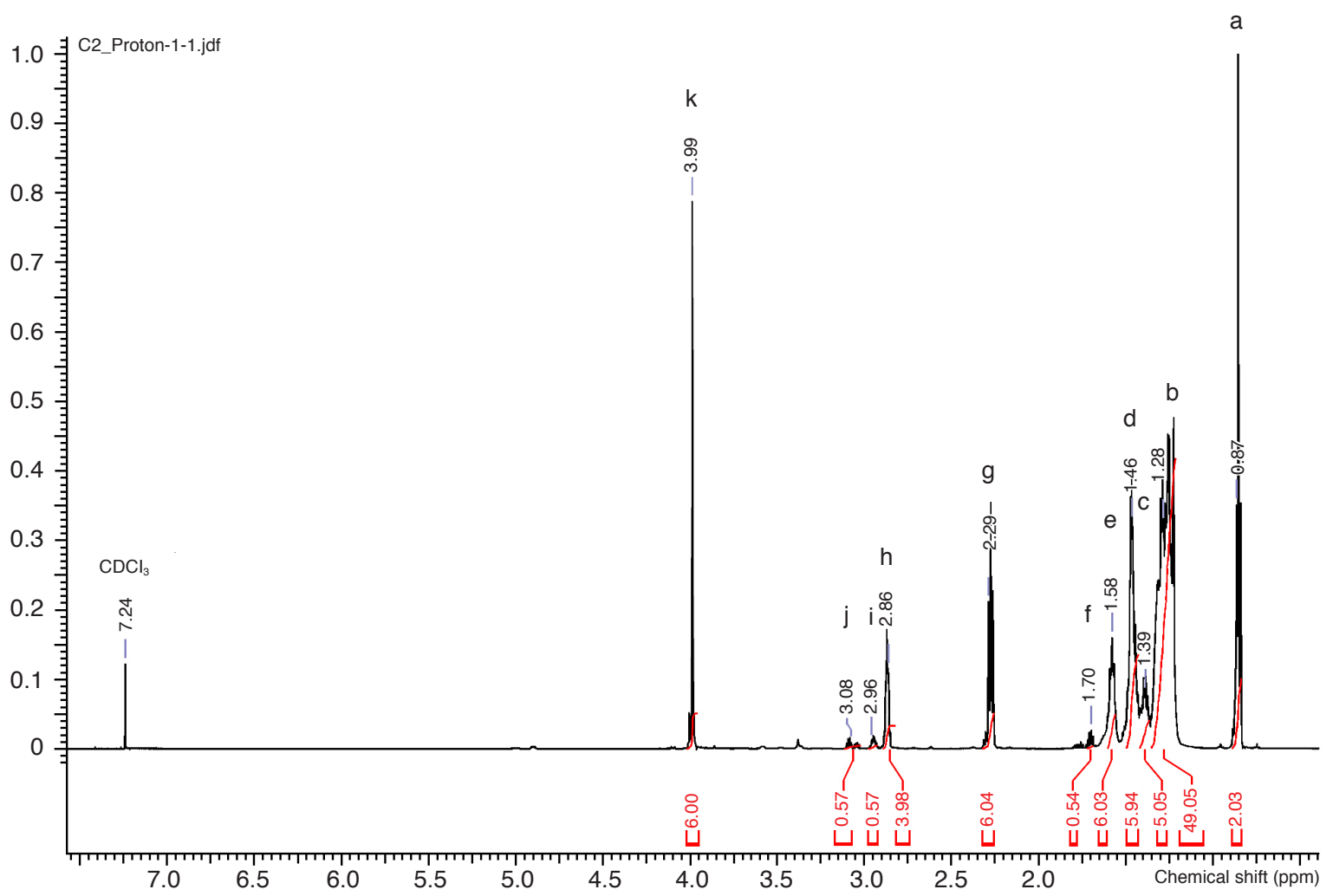

Figure 6. Integration of ${ }^{1} \mathrm{H}-\mathrm{NMR}$ spectrum of epoxidised TMP trioleate with epoxide contents of $4.33 \pm 0.18 \%$. The reaction conversion was determined based on the epoxidation of the double bond, present in the fatty acids chain of TMP esters, into oxirane oxygen. The integrations of the double bonds at $\delta 5.27-5.41 \mathrm{ppm}$ in $H_{a}$ and the epoxides at $\delta 2.82-2.90 \mathrm{ppm}, \delta 2.92-2.97 \mathrm{ppm}$ and $\delta 3.01-3.11$ ppm were made by taking the signals of protons $\left(\alpha-\mathrm{CH}_{2}-\mathrm{O}-\mathrm{C}\right)$ in $\mathrm{H}_{b}$ at $\delta 3.95-4.04 \mathrm{ppm}$ as internal standards. The area of the internal standard was calibrated as 6.00 as the number of $\alpha$-protons is 6. 
$\left(-\mathrm{CH}_{2} \mathrm{CH}_{2}-\mathrm{CHOCH}-\mathrm{CH}_{2} \mathrm{CH}_{2}-\right)$ which is deshielded due to strong anisotropy effect of the adjacent oxygen of the epoxy group (Salih et al., 2015).

The $\mathrm{C}=\mathrm{C}$ unsaturations in TMP trioleate found at $\delta 2.73-2.77$ ppm and $\delta 5.27-5.38$ ppm were largely replaced with the epoxy group. The signals of epoxides appeared around $\delta 2.83-3.11$ ppm, which was likely related to the formation of the methine protons in the epoxidised TMP trioleate comprised of TMP 9, 10, 12, 13-diepoxystearic acid (-CHOCH$\left.\mathrm{CH}_{2}-\mathrm{CH}=\mathrm{CH}-\right)$ and TMP 9, 10-epoxystearic acid (-CHOCH-). The presence of monoepoxide rings in the epoxy TMP trioleate was confirmed with methine protons found at $\delta 2.83-2.89 \mathrm{ppm},(-\mathrm{CHOCH}-)$ and $\left(-\mathrm{CHOCH}-\mathrm{CH}_{2} \mathrm{CH}=\mathrm{CH}-\right)$ or $\mathrm{H}_{\mathrm{h}}$ in the structure. It has integration values of 4 protons which suggested that the feedstock TMP trioleate has mostly bisubstituted oleic acid moiety. The chemical shift of diepoxides in epoxidised TMP linoleic or TMP 9, $10,12,13$-diepoxystearic acid was found at $\delta 2.92$ - 2.98 ppm of $\mathrm{H}_{\mathrm{i}}$ (-CHOCH-CH$\left.-\mathrm{CHOCH}-\right)$ and $\delta 3.02-3.11$ ppm of $\mathrm{H}_{\mathrm{j}}$ (-CHOCH$\left.-\mathrm{CH}_{2}-\mathrm{CHOCH}-\right)$ respectively. The protons at the $\delta 1.68-1.73 \mathrm{ppm}$ of $\mathrm{H}_{\mathrm{f}}$ (- $\left.\mathrm{CHOCH}-\mathrm{CH}_{2}-\mathrm{CHOCH}-\right)$ are deshielded primarily due to the effect of the secondary epoxy group which indicated epoxy linoleic fatty acid moiety in the TMP 9, 10, 12, 13-diepoxystearic acid (Sharma et al., 2006). The TMP trioleate and epoxidised TMP trioleate NMR results were found to be in a good agreement with the results obtained from FTIR. The total integration value obtained from the epoxides group was 5.12 and used to enumerate the DOE.

Epoxides were recognised as secondary oxidation products that have been formed from the rearrangement of the alkoxyl radicals or from intramolecular radical substitution with peroxides (Frankel, 1984; Yin et al., 2011). Until recently, epoxides have been considered as intermediates formed from peroxyl radicals directly, independent of hydroperoxides (Schaich, 2012). The chemical shifts of epoxides ( $\delta 2.90-3.24$ ppm) were distinct from other oxidation products including alcohols ( $\delta 3.43-3.62 \mathrm{ppm}$ ), conjugated dienes ( $\delta 5.4-6.58$ ppm), double bonds conjugated with carbonyls

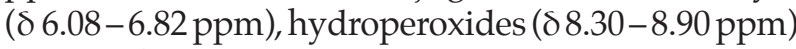
and aldehydes ( $\delta 9.49$ - 9.79 ppm) (Xia et al., 2015). Ally radicals can be formed very easily in the oleic acid portion of TMP ester due to the existence of $\mathrm{C}=\mathrm{C}$ bonds that would be converted to peroxide causing oxidative deterioration but the hydroperoxides were not detected in the ${ }^{1} \mathrm{H}-\mathrm{NMR}$ (Wu et al., 2000).

Figure 7 shows the ${ }^{13} \mathrm{C}-\mathrm{NMR}$ spectrum of the epoxidised TMP trioleate structure where the deuterated chloroform showed a signal at $77.0 \mathrm{ppm}$. The chemical shift at $\delta 7.54-7.58$ ppm corresponded to terminal methyl carbon of $\mathrm{C}_{1}\left(-\mathrm{CCH}_{2} \mathrm{CH}_{3}\right)$ at the TMP molecule. However the terminal methyl carbon of attached fatty acids corresponded to $\delta 14.25-$ 14.29 ppm of $\mathrm{C}_{2}\left(-\mathrm{CH}_{2} \mathrm{CH}_{2} \mathrm{CH}_{2} \mathrm{CH}_{3}\right)$. The bridging methylene carbon adjacent to the terminal methyl carbon of attached fatty acids are at $\delta 22.82-22.86$ ppm of $\mathrm{C}_{3}\left(-\mathrm{CH}_{2} \mathrm{CH}_{2} \mathrm{CH}_{2} \mathrm{CH}_{3}\right)$. The chemical shift at $\delta 25.04-25.08 \mathrm{ppm}$ referred to $\beta$ position of bridging methylene carbon $\mathrm{C}_{4}\left(-\mathrm{CH}_{2}-\mathrm{CH}_{2} \mathrm{C}=\mathrm{O}-\right)$ at the fatty acid chain. The chemical shift $\delta 26.78-26.82$ ppm referred to the bridging methylene carbon $\beta$-position with respect to the epoxy functionality at $\mathrm{C}_{5}\left(-\mathrm{CH}_{2}-\right.$ $\left.\mathrm{CH}_{2} \mathrm{CH}-\mathrm{O}-\mathrm{CH}-\right)$. The chemical shift $\delta 28.00-28.04$ ppm corresponded to bridging methylene carbon at $\gamma$-position with respect to the ester functionality as located at $\mathrm{C}_{6}\left(-\mathrm{CH}_{2}-\mathrm{CH}_{2} \mathrm{CH}_{2} \mathrm{C}=\mathrm{O}-\right)$ in the structure while $\delta 29.38-29.42$ ppm matched the subsequent methylene carbon next to $\mathrm{C}_{6}$ which is marked as $\mathrm{C}_{7}$ $\left(-\mathrm{CH}_{2}-\mathrm{CH}_{2} \mathrm{CH}_{2} \mathrm{CH}_{2} \mathrm{C}=\mathrm{O}-\right)$. The chemical shift $\delta 32.02$ - $32.06 \mathrm{ppm}$ pointed to the $\alpha$-carbon adjacent to the epoxy functionality is found at of $\mathrm{C}_{8}\left(-\mathrm{CH}_{2} \mathrm{CH}\right.$ $\mathrm{O}-\mathrm{CH}-$ ) which has shifted downfield due to the adjacent epoxy group. The $\alpha$-carbon adjacent to the carbonyl functionality found at $\delta 34.34-34.38 \mathrm{ppm}$ labelled as $\mathrm{C}_{9}\left(-\mathrm{CH}_{2} \mathrm{CH}_{2} \mathrm{C}=\mathrm{O}-\right)$ while on the opposite end the carbon adjacent to the oxygen is located at $\delta 63.85-63.89 \mathrm{ppm}$ of $\mathrm{C}_{11}\left(-\mathrm{CCH}_{2} \mathrm{OC}=\mathrm{OCH}_{2}-\right)$. The deshielded carbon attached to oxirane oxygen showed at $\delta 57.33-57.37$ ppm of $\mathrm{C}_{10}\left(-\mathrm{CH}_{2} \mathrm{CH}-\mathrm{O}-\right.$ $\mathrm{CH}-)$ which indicated epoxy moiety. The chemical shift at $\delta 173.60-173.64 \mathrm{ppm}$ corresponded to the mostly deshielded carbonyl group carbon as labelled as $\mathrm{C}_{12}\left(-\mathrm{CCH}_{2} \mathrm{OC}=\mathrm{O}-\right)$ in the structure.

The TGA curves of the samples are shown in Figure $8 a$ and the DTG thermogram are shown in Figure $8 b$ while the values of $\mathrm{T}_{\text {onset }} \mathrm{T}_{\text {end set }} \mathrm{T}_{50 \%}$ and $\mathrm{T}_{\max }$ are tabulated in Table 3. Beyond the onset temperature with gradual increase in temperature considerable weight loss was observed. TGA curves of both TMP trioleate and epoxidised TMP trioleate exhibited similar characteristic. This indicated that the addition of epoxy rings did not change the degradation mechanism of the epoxidised TMP trioleate but only influence the degree of degradation. It can be observed in Figure $8 a$ and Table 3 that the oxirane moiety speed up the initial degradation of epoxidised TMP trioleate as the onset temperature decreased to $314.12^{\circ} \mathrm{C}$ as compare with TMP trioleate at $320.53^{\circ} \mathrm{C}$ due to the addition of oxygen group, removal of unsaturation in the TMP trioleate fatty acid chain, chain entanglement and increased intramolecular attraction between molecules (Borugadda and Goud, 2014; Chuayjuljit et al., 2015). From Figure $8 b$, there is only one exothermic peak for the TMP trioleate which indicated degradation of the sample in a single continuous step but two exothermic peaks were observed for epoxidised TMP trioleate. By comparing these two samples, there are only one exothermic peak for the TMP trioleate at $\mathrm{T}_{\max }$ $441.08^{\circ} \mathrm{C}$ and the second exothermic peak for the epoxidised TMP trioleate started at approximately the same temperature as TMP trioleate at $\mathrm{T}_{\max }$ 

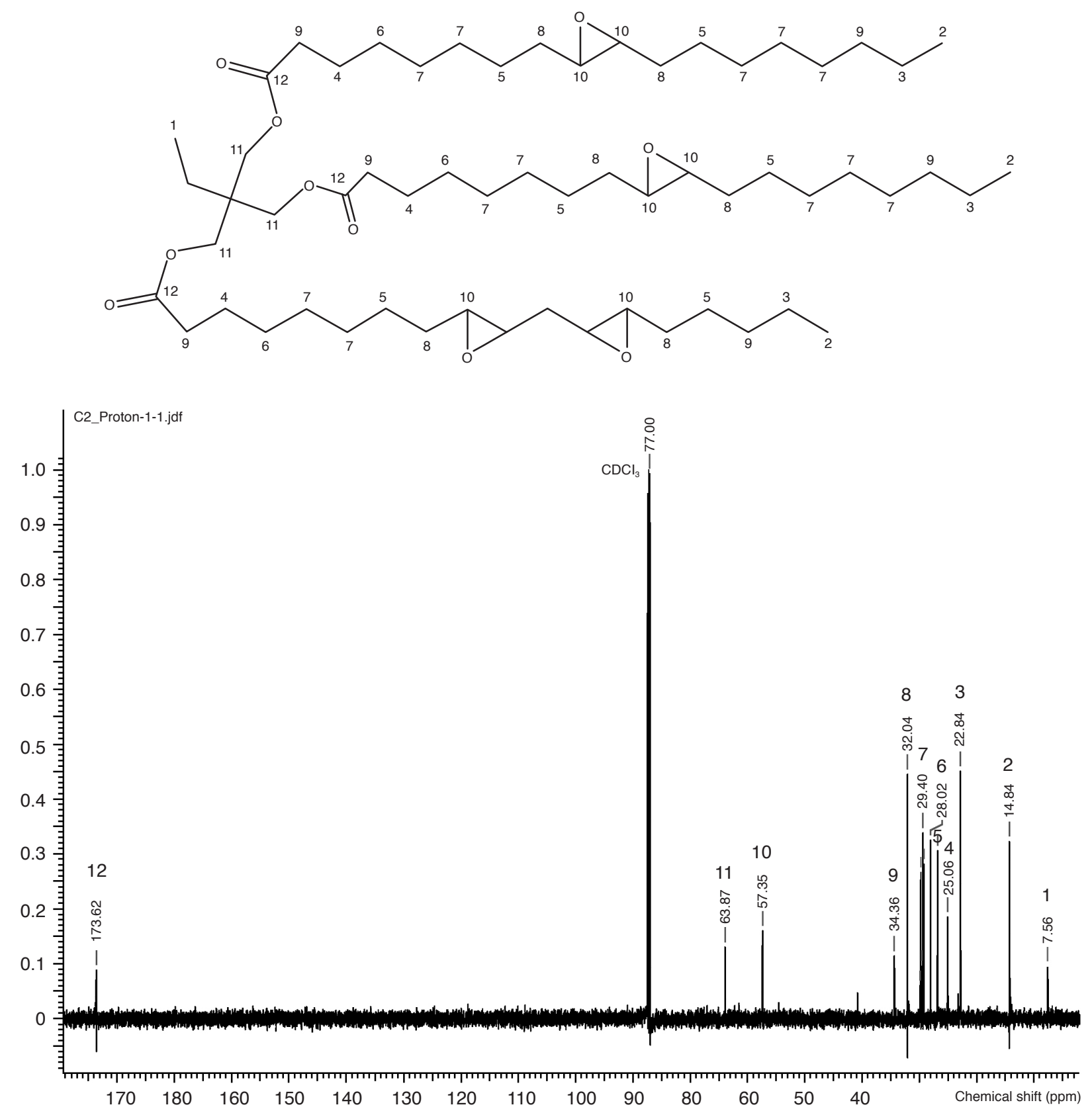

Figure 7. The ${ }^{13} \mathrm{C}-\mathrm{NMR}$ spectrum of epoxidised TMP trioleate which serves as a confirmation of structure. The $\delta 57.35$ ppm indicated carbon with epoxy (-CHOCH-) moiety attached in $\mathrm{C}_{10}$. TGA was performed to evaluate the thermal stability of TMP trioleate and its oxidised form.

$439.68^{\circ} \mathrm{C}$. The first peak was attributed to weight loss due to consumption of epoxide rings at $384.20^{\circ} \mathrm{C}$ and the second peak was due to degradation of TMP trioleate. Aside from the $\mathrm{T}_{\max }$ the $\mathrm{T}_{50 \%}$ and $\mathrm{T}_{\text {end set }}$ were all shifted to the lower temperatures after epoxidation process suggesting the lower thermal stability of the oxirane rings. The $50 \%$ weight loss was recorded at $440.17^{\circ} \mathrm{C}$ for TMP trioleate while epoxidised TMP trioleate fared lower at $425.33^{\circ} \mathrm{C}$. Accordingly to Chiniwalla et al., the weight loss correlates directly to the level of epoxy attached to the fatty acids backbone, suggested that the volatile species oxygen associated with the epoxide groups are responsible for the weight loss (Chiniwalla et al., 2003). Both the structures yielded char residue values of $0.42 \%$ to $0.49 \%$ at the end of the thermal decomposition process.

\section{CONCLUSION}

The present work has provided a systematic study of the effect of the epoxidation process of TMP trioleate on the characteristic of the epoxidised TMP trioleate. The influence of molar ratio of ethylenic unsaturation in TMP trioleate to formic acid and 


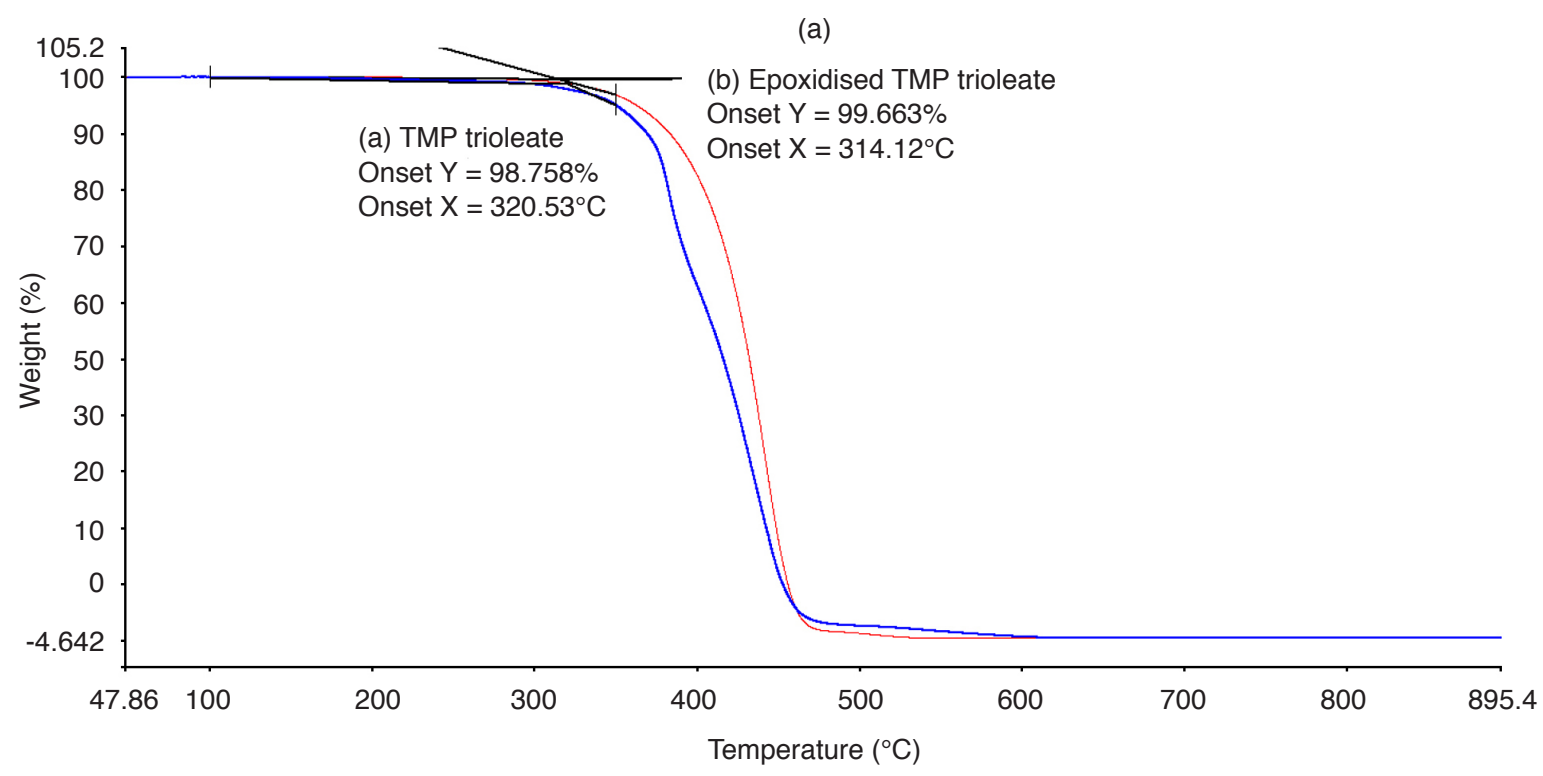

(b)

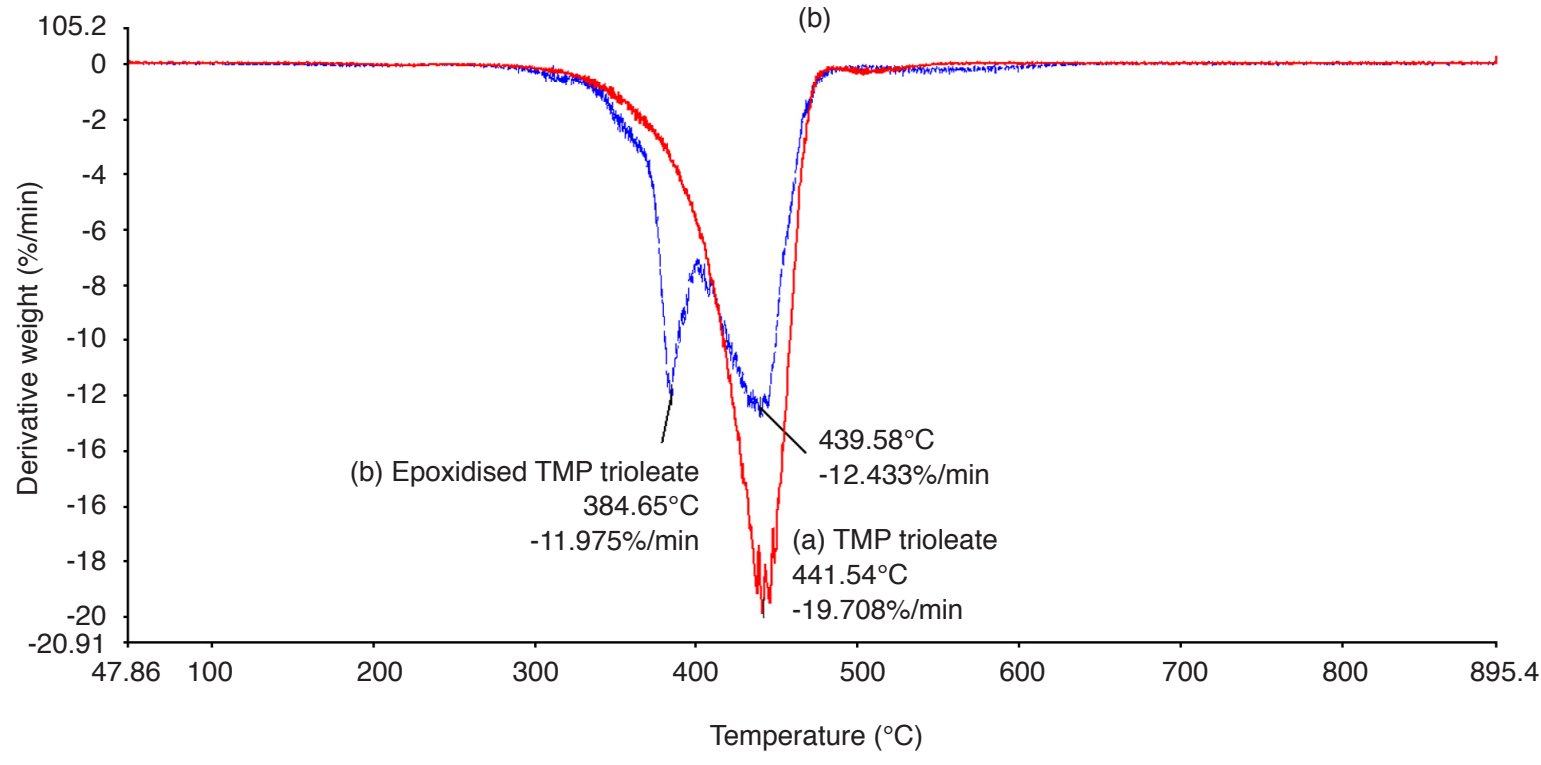

Figure 8. (a) TG and (b) DTG thermograms of TMP trioleate and epoxidised TMP trioleate

TABLE 3. TERMAL DECOMPOSITION TEMPERATURES OF TRIMETHYLOLPROPANE (TMP) TRIOLEATE AND EPOXIDISED TMP TRIOLEATE

\begin{tabular}{lcccc}
\hline \multirow{2}{*}{ Sample } & \multicolumn{4}{c}{ Thermal degradation $\left({ }^{\circ} \mathrm{C}\right)$} \\
\cline { 2 - 5 } & $\mathrm{T}_{\text {onset }}$ & $\mathrm{T}_{50 \%}$ & $\mathrm{~T}_{\text {end set }}$ & $\mathrm{T}_{\text {max }}$ \\
\hline TMP trioleate & 320.53 & 440.17 & 461.22 & 441.08 \\
Epoxidised TMP trioleate & 314.12 & 425.33 & 459.20 & 439.68 \\
\hline
\end{tabular}

hydrogen peroxide were carried out and had a strong influence on the resulting yields. Generally, the high ratio of formic acid to ethylenic unsaturation in TMP trioleate is unfavourable for in situ epoxidation as the reaction generated free fatty acids through hydrolysis and the high oxidising potential of peroxyformic acid could cause degradation of oxirane ring. The chemical shifts of epoxides were distinct from other oxidation products including conjugated dienes, hydroperoxides and others.
The ${ }^{1} \mathrm{H}-\mathrm{NMR}$ can be used to detect epoxides and diepoxides in TMP 9, 10-epoxystearic acid and TMP 9, $10,12,13$-diepoxystearic acid respectively. It has been observed that the initial thermal stability of epoxidised TMP trioleate is lower than TMP trioleate and performed poorer at higher temperatures as volatile oxygen species in the epoxy moiety participated in the thermal degradation. TMP trioleate was epoxidised successfully, confirmed by FTIR and the degree of epoxidation was quantified by NMR. 


\section{ACKNOWLEDGEMENT}

The authors are grateful to the Director-General of MPOB for permission to publish this article.

\section{REFERENCES}

Adhvaryu, A; Liu, Z and Erhan, S Z (2002). Epoxidized soybean oil as a potential source of hightemperature lubricants. Ind. Crops Prod., 15: 247-254. DOI: 10.1016/S0926-6690(01)00120-0.

American Oil Chemists' Society (2009). AOCS Official Method CD 9-57. Official Methods and Recommended Practices of the AOCS (Firestone, D, ed.). $6^{\text {th }}$ ed. American Oil Chemists' Society Press, Urbana, IL, USA.

Benecke, H P; Vijayendran, B R and Elhard, J D (2004). Patent plasticisers derived from vegetable oils. US patent 6797753 B2.

Boquillon, N (2006). Use of an epoxidized oilbased resin as matrix in vegetable fibers-reinforced composites. J Appl. Polym. Sci., 101: 4037-4043. DOI: 10.1002 / app.23133.

Borugadda, V B and Goud, V V (2014). Epoxidation of castor oil fatty acid methyl esters (COFAME) as a lubricant base stock using heterogeneous ionexchange resin (IR-120) as a catalyst. Energy Procedia, 54: 75-84. DOI: 10.1016/j.egypro.2014.07.249.

Campanella, A; FontaninI, C and Baltanas, M A (2008). High yield epoxidation of fatty acid methyl esters with performic acid generated in-situ. Chem. Eng. J., 144: 466-475. DOI: 10.1016/j.cej.2008.07.016.

Cheong, M Y; Ooi, T L; Ahmad, S; Yunus, W M Z W and Kuang, D (2009). Synthesis and characterization of palm-based resin for UV coating. J. Appl. Polym. Sci., 111: 2353-2361. DOI: 10.1002/ app.29257.

Chieng, B W; Ibrahim, N A, Then, Y Y and Loo, Y Y (2017). Epoxidized Jatropha oil as a sustainable plasticizer to poly(lactic acid). Polymers, 9: 204-213. DOI: 10.3390 / polym9060204.

Chiniwalla, P; Bai, Y; Elce, E; Shick, R; Mcdougall, W C; Allen, S A B and Kohl, P A (2003). Crosslinking and decomposition reaction of epoxide functionalized polynorbornene. Part I. FTIR and thermogravimetric analysis. J Appl. Polym. Sci., 89: 568-577. DOI: 10.1002 / app.23133.

Chuayjuljit, S; Nutchapong, T; Saravari, $\mathrm{O}$ and Boonmahitthisud, A (2015). Preparation and characterization of epoxidized natural rubber and epoxidized natural rubber/carboxylated styrene butadiene rubber blends. J. Met. Mater. Miner., 25: 27-36. DOI: 10.14456/jmmm.2015.4.

Farkas, F K (1999). The industrial paint-making process. Paint and Surface Coatings (Lambourne, $\mathrm{R}$ and Strivens, T A eds.). Woodhead Publishing Ltd, Cambridge, England. p. 286-329.

Frankel, E N (1984). Chemistry of free radical and singlet oxidation of lipids. Prog. Lipid Res., 23: 197221. DOI: 10.1016/0163-7827(84)90011-0.

Gall, R J and Greenspan, F P (1955). Epoxy compounds from unsaturated fatty acids esters. Ind. Eng. Chem., 47: 147-148. DOI: 10.1021/ie50541a045.

Goud, V V; Patwardhan, A V; Dinda, S and Pradhan, N C (2007). Kinetics of epoxidation of Jatropha oil with peroxyacetic and peroxyformic acid catalyzed by acidic ion exchange resin. Chem. Eng. Sci., 62: 4065-4076. DOI: 10.1016/j. ces.2007.04.038.

Hassan, H A; Ismail, T N M T; Sattar, M N; Hoong, S S; Ooi, T L; Ahmad, S and Cheong, M Y (2011). Process to produce polyols. US patent 7932409.

Khot, S N; Lanscala, J L; Can, E; Morye, S S; Williams, G I; Palmese, G R; Kusefoglu, S H and Wool, R P (2001). Development and application of triglyceride based polymers and composites. J. Appl. Polym. Sci., 82: 703-723. DOI: 10.1002/app.1897.

Li, F; Hanson, M V and Larock, R C (2001). Soybean oil-divinylbenzene thermosetting polymers: Synthesis, structure, properties and their relationships. Polymer, 42: 1567-1579. DOI: 10.1016/ S0032-3861(00)00546-2.

Li, F and Larock, RC (2001). New soybean oil - styrenedivinylbenzenethermosettingcopolymers. I.Synthesis and characterization. J. Appl. Polym. Sci., 80: 658-670. DOI: $10.1002 / 1097-4628(20010425) 80: 4<658:: A I D A P$ P1142>3.0.CO; 2-D.

Li, F and Larock, R C (2000). New soybean oilstyrene-divinylbenzene thermosetting copolymers. II. Dynamic mechanical properties. J. Polym. Sci., Part B: Polym. Phys., 38: 2721-2738. DOI: 10.1002/1099-0488(20001101)38:21<2721::AIDPOLB 30>3.0.CO; 2-D.

Li, F and Larock, R C (2001). New soybean oilstyrene-divinylbenzene thermosetting copolymers. III. Tensile stress-strain behavior. J. Polym. Sci., Part B: Polym. Phys., 39: 60-77. DOI:10.1002/10990488(20010101)39:1<60::AIDPOLB60>3.0.CO;2-K. 
Li, F and Larock, R C (2002). New soybean oilstyrene-divinylbenzene thermosetting copolymers. IV. Good damping properties. Polym. Adv. Technol., 13: 436-449. DOI: 10.1002/ pat.206.

Li, F and Larock, R C (2002). New soybean oilstyrene-divinylbenzene thermosetting copolymers. V. Shape memory effect. J. Appl. Polym. Sci., 84: 15331543. DOI: 10.1002 / app.10493.

Liu, ZS; Erhan, S Z; Akin, D E and Barton, F E (2006). 'Green' composites from renewable resources: Preparation of epoxidized soybean oil and flax fiber composites. J. Agric. Food. Chem., 54: 2134-2137. DOI: $10.1021 /$ jf0526745.

Liu, Z S; Erhan, S Z; Xu, J and Calvert, P D (2002). Development of soybean oil-based composites by solid free-form fabrication method: Epoxidized soybean oil with bis or polyalkyleneamine curing agents system. J. Appl. Polym. Sci., 85: 2100-2107. DOI: 10.1002 / app.10763.

Lu, J; Khot, S and Wool, R P (2005). New sheet molding compound resins from soybean oil. I. Synthesis and characterization. Polymer, 46: 71-80. DOI: $10.1016 /$ j.polymer.2004.10.060.

Luo, Q; Liu, M; Xu, Y; Ionescu, M and Petrovi, Z $S$ (2011). Thermosetting allyl resins derived from soybean oil. Macromolecules, 11: 7149-7157. DOI: $10.1021 / \mathrm{ma} 201366 \mathrm{e}$

Naidir, F; Yunus, R; Rashid, U; Masood, H; Ghazi, T I M and Ramli, I (2012). Eur. J. Lipid Sci. Technol., 114: 816-822. DOI: 10.1002 / ejlt.201100222.

Prileschajew, N (1909). Oxydation ungesättigter verbindungen mittels organischer superoxyde. Ber. Dtsch. Chem. Ges., 42: 4811-4815. DOI: $10.1002 /$ cber.190904204100.

Saithai, P; Lecomte, J; Dubreucq, E and Tanrattanakul, V (2013). Effects of different epoxidation methods of soybean oil on the characteristics of acrylated epoxidized soybean oil-co-poly(methyl methacrylate) copolymer. Express Polym. Lett., 7: 910-924. DOI: 10.3144/expresspolymlett.2013.89.

Salih, A M; Ahmad, M; Ibrahim, N A; Dahlan, K Z M; Tajau, R; Mahmood, M H and Yunus, W M Z W (2015). Synthesis of radiation curable palm oilbased epoxy acrylate: NMR and FTIR spectroscopic investigations. Molecules, 20: 14191-14211. DOI: 10.3390 / molecules200814191.

Schaich, K M (2012). Thinking outside the classical chain reaction box of lipid oxidation. Lipid Technol., 24: 55-58. DOI: 10.1002/lite.201200170.

Scotti, N; Ravasio, N; Psaro, R; Evangelisti, C; Dworakowska, S; Bogdal, D and Zaccheria, F (2015). Copper mediated epoxidation of high oleic natural oils with a cumene- $\mathrm{O}_{2}$ system. Catal. Commun., 64: 80-85. DOI: 10.1016/j.catcom.2015.02.008.

Sharma, B; Adhvaryu, A; Liu, Z and Erhan, S (2006). Chemical modification of vegetable oils for lubricant applications. J. Amer. Oil Chem. Soc., 83: 129-136. DOI: $10.1007 /$ s11746-006-1185-z.

Tanrattanakul, V and Saithai, P (2009). Mechanical properties of bioplastics and bioplastic-organoclay nanocomposites prepared from epoxidized soybean oil with different epoxide contents. J. Appl. Polym. Sci., 114: 3057-3067. DOI: 10.1002/ app.30842.

Wu, X; Zhang X; Yang, S; Chen, $\mathrm{H}$ and Wang, D (2000). The study of epoxidised rapeseed oil used as a potential biodegrable lubricant. J. Amer. Oil Chem. Soc., 77: 561-563. DOI: 10.1007/ s11746-000-0089-2.

Xia, W; Budge, S M and Lumsden, M D (2015). New ${ }^{1} \mathrm{H}$ NMR-based technique to determine epoxide concentrations in oxidized oil. J. Agric. Food. Chem., 63: 5780-5786. DOI: 10.1021 / acs.jafc.5b01719.

Xiao, P; Sengupta, P and Webster, D C (2011). High biobased content epoxy-anhydride thermosets from epoxidized sucrose esters of fatty acids. Biomacromolecules, 12: 2416-2428. DOI: 10.1021/ bm200549c.

Xu, J; Liu, Z and Erhan, S Z (2008). Viscoelastic properties of a biological hydrogel produced from soybean oil. J. Amer. Oil Chem. Soc., 85: 285-290. DOI: 10.1007 / s11746-008-1193-2.

Yin, H; Xu, L and Porter, N A (2011). Free radical lipid peroxidation: Mechanisms and analysis. Chem. Rev., 111: 5944-5972. DOI: 10.1021/cr200084z.

Yunus, R; Ooi, T L; Fakhru'l-Razi, A and Basri, S (2002). A simple capillary column GC method for analysis. J. Amer. Oil Chem. Soc., 79: 1075-1080. DOI: 10.1007/ s11746-002-0606-3. 